\title{
A review paper on decision support system/expert system developed on mango
}

\author{
Meenakshi Malik*, Mukesh Sehgal, A.K. Kanojia and R. V. Singh
}

National Research Centre for Integrated Pest Management, New Delhi, India

\section{ARITCLE INFO}

Received : 19.1 .2018

Accepted : 28.03.2018

\section{KEY WORDS :}

Agriculture, Expert system, Decision support system, Decision maker, Mango

*Corresponding author: minaxi.2007@gmail.com

\begin{abstract}
Agriculture being a primary source of income in the country is the backbone of Indian economy. And being a primary and important source of income, ICT has played an significant role in the extension services and information sharing in agriculture. To get high yield and high profit, farmers require advance or expert knowledge to take decision during soil preparation, seed selection, fertilizer management, pesticide management, water scheduling, weed management. Decision Support System are now being used into agriculture sector and are proved to be most efficient tool for interchange of knowledge and facts. This paper explains need of DSS in agriculture and review of various DSS/expert systems in agriculture. A Project on DSS on Mango for U.P. state according to various Agro-climatic zones of India has been proposed as mango is one of most important horticultural crop and has a wide distribution all over the country.
\end{abstract}

How to view point the article : Malik, Meenakshi, Sehgal, Mukesh, Kanojia, A.K. and Singh, R.V. (2018). A review paper on decision support system/expert system developed on mango. Internat. J. Plant Protec., 11(1) : 119-123, DOI : 10.15740/HAS/IJPP/11.1/119-123. 